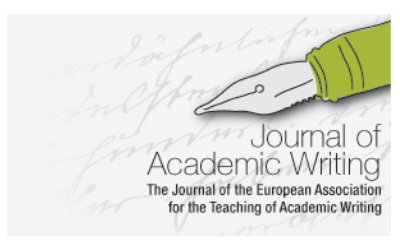

Journal of Academic Writing

Vol. 8 No 2 Winter 2018, pages 233-236 http://dx.doi.org/10.18552/joaw.453

\title{
Exploring the Development of Writerly Identity Through the Use of Blogging
}

\author{
David Hindley \\ Nottingham Trent University, UK \\ Lisa Clughen \\ Nottingham Trent University, UK
}

\begin{abstract}
This paper discusses implementation of blog writing as a formative assessment within a final year undergraduate module. Drawing on students' perceptions and experiences, it proposes that blogging offers a more inclusive writing genre for Higher Education than traditional forms of academic scholarship.
\end{abstract}

\section{Introduction}

Academic writing is a staple university practice required across disciplines to determine student success. However, as colleagues of over twenty years' standing in Higher Education, we have repeatedly heard eloquent, thoughtful students voice deep anxieties about it. The overall picture, in fact, is that students frequently experience academic writing as being exclusionary and alienating (see Mann 2001). This idea has long been highlighted by literacy scholars, with two authors in particular informing the ameliorative, more inclusive approach advocated here. The first is Elbow (2014), who invites us to reconsider the alienating language of academic writing and champions genres that use the students' 'Vernacular Eloquence' - their own, familiar language. The second is English (2011) who argues for the incorporation of a wider range of genres into our learning and teaching repertoire. Such an approach, which English calls 'Regenring', opens possibilities for students to author their scripts, rather than remain alienated from them.

Blogging is one such method of Regenring, providing a platform where the style of writing sits somewhere between the formal and informal (Morris 2018). Furthermore, there is a growing awareness that blogging may provide students with an alternative place to create academic identities that are more attainable and less elusive than traditional ones (Hindley and Clughen 2018).

\section{Students as Bloggers}

The intervention was conducted on a final year undergraduate module entitled Contemporary Issues in Sports Practice at a large, post-1992 university in the UK. The students on the module (82) were required to submit an individual blog post on a sporting issue of their choosing. In keeping with the blogging genre, contributions had to be short (600 words) and incorporate web links, images and hashtags. Students were also asked to comment on peers' blog posts, as well as attract readers to their own blog. This made up the formative part of the assessment, which fed directly into the summative assignment: a 3,000-word sociological analysis of their chosen issue and, for a third of the marks, a reflection on the process of blog writing and its contribution to their final analysis. 
The practicalities of how to blog were covered in a series of interactive workshops facilitated by a module tutor who is himself an experienced blogger. He also took on the role of editor and gatekeeper, publishing the students' work online using Tumblr, a microblogging site.

\section{Evidence of Effectiveness and Impacts}

Data were collected using a mixed methods approach, incorporating an online survey of participants ( $N=33)$, a focus group $(\mathrm{N}=5)$, and students' written reflections $(\mathrm{N}=82)$. The purpose of the study was to explore the students' experiences of blogging. A snapshot of the survey data (see Table 1) provides an illustration of how the cohort reflected positively on the process and experience of writing a blog in comparison to a traditional essay.

Table 1: Descriptive statistics (means and standard deviations) from the online survey $(\mathrm{N}=33)$

\begin{tabular}{|l|c|c|}
\hline $\begin{array}{l}\text { Statements (all ranked 0-10 where higher values indicate more } \\
\text { agreement) }\end{array}$ & SD \\
\hline \begin{tabular}{l|l|}
\hline Essays are a much more academic form of assessment than blogs \\
It was easier to write the blog than a traditional academic essay
\end{tabular} & 8.69 & 1.74 \\
\hline $\begin{array}{l}\text { The blog was a more engaging form of assessment than an academic } \\
\text { essay }\end{array}$ & 7.66 & 2.82 \\
\hline $\begin{array}{l}\text { I felt I could express myself more freely in the blog than in my } \\
\text { academic essays }\end{array}$ & 7.69 & 2.48 \\
\hline I felt I could be more creative in my blog than in an essay & 8.03 & 2.14 \\
\hline I enjoyed writing my blog more than writing an academic essay & 7.84 & 2.46 \\
\hline
\end{tabular}

*participants scored significantly higher than the scale mid-point (5) for all these items, indicating high levels of agreement with the statements

Similarly, drawing on the qualitative data, respondents reflected on their experiences of blogging as a medium which afforded them greater freedom to 'write as yourself' (student reflection). The interactive nature of the blog helped them appreciate they were academics in their own right.

The most rewarding part of the experience was seeing a debate form on my social media account. I felt like an expert who was actively educating and encouraging people to talk about grassroots disability sport and the wider issues of disability (student reflection).

The perceived informality of blogging was a recurring theme, with 'relaxing' and 'enjoyable' being the most common descriptions of the experience. In this sense, blogging serves as a bridge between writing that students perceive as pleasurable and fun, that allows for the free flow of voice, and writing they consider to be work.

The notion of creativity was also commented on, often interwoven with the idea that blogging provides a greater degree of autonomy than a conventional essay.

In comparison to writing an essay, I found the blog a lot easier, and a greater sense of freedom. I felt as though I could shape the blog with my own thoughts, with my opinions being informed by academic references (student reflection).

As previously, this student's account captures some of the tensions identified by literacy scholars who contend that conventional forms of academic writing and assessment are prohibitive. Moreover, echoing the arguments proposed by English (2011), from a student's perspective the experience of writing differently for an academic purpose can be both empowering and, indeed, transformative. 


\section{Reflections}

The findings from this intervention highlight the potential blogging affords as a form of writing that sits 'somewhere in between' (Morris 2018). We contend that, by allowing the students to experiment with an alternative writing form that uses 'the language that comes most easily to mind and mouth' (Elbow 2012: 6), blogging has the potential to loosen the constricting 'straitjacket of genre' (Hamilton and Pitt 2009). We conclude with two comments from our student participants to demonstrate this. The first, commenting on the practice of essay writing, concedes 'I feel like I am trying to speak as somebody I don't understand'. The second, reflecting on their blogging experience, remarked 'I felt I was able to offer my own personal views and be myself, which I don't often feel comes across when participating in academic writing'. Where essays can alienate so that student authors feel like they are writing as someone else, blogging can make them feel like experts with a voice.

\section{Acknowledgements}

We would like to thank The Trent Institute for Learning and Teaching (TILT) at Nottingham Trent University for funding the research discussed in this paper. We would also like to thank all the students that took part in the study. 


\section{References}

Elbow, P. (2012) Vernacular Eloquence: What Speech Can Bring to Writing. Oxford: Oxford University Press

English, F. (2011) Student Writing and Genre: Reconfiguring Academic Knowledge. London: Bloomsbury

Hamilton, M., and Pitt, K. (2009) 'Creativity in Academic Writing: Escaping from the Straitjacket of Genre?'. in Why Writing Matters. Issues of Access and Identity in Writing Research and Pedagogy. ed. by Carter, A., Lillis, T., and Parkin, S. Amsterdam: John Benjamins, 61-80

Hindley, D., and Clughen, L. (2018) 'Yay! Not Another Academic Essay!' Blogging as an Alternative Academic Genre'. Journal of Writing in Creative Practice 11 (1), 83-97

Mann, S. (2001) 'Alternative Perspectives on the Student Experience: Alienation and Engagement'. Studies in Higher Education 26 (1), 1-19

Morris, M.A. (2018). 'Somewhere in Between: Blogging as an Intermediate and Accessible Space'. Journal of Writing in Creative Practice 11 (1), 67-81 